Original Research Paper

\title{
Relationship between Anti-Ds-DNA Antibodies and Abnormal Kidney Function Tests in Patients with Lupus Nephritis
}

\author{
${ }^{1}$ Falah Salim Manhal and ${ }^{2}$ Hawra'a Adnan Mohammed \\ ${ }^{1}$ College of Health and Medical Technology, Middle Technical University, Baghdad, Iraq \\ ${ }^{2}$ Al-Kadhimiyah Teaching Hospital, Baghdad, Iraq
}

Article history

Received: 22-03-2016

Revised: $30-04-2016$

Accepted: 20-05-2016

Corresponding Author:

Falah Salim Manhal

College of Health and Medical

Technology, Middle Technical

University, Baghdad, Iraq

Email: falahsalim@yahoo.com

\begin{abstract}
The majority of patients with Lupus Nephritis (LN) usually have abnormal findings of kidney function tests. Severe glomerular damage may be observed in some patients and requires prompt therapeutic interventions. High titer levels of anti-ds-DNA antibodies may correlate to some extent with disease activity in lupus nephritis patients. The purpose of this study was to evaluate the relationship between anti-dsDNA antibody titers and abnormal kidney function tests in patients with lupus nephritis. A total of seventy patients with lupus nephritis and fifty healthy controls were enrolled in this study. Blood samples were collected and labeled from study patients and controls for certain hematological, biochemical and immunological investigations. Anti-dsDNA antibodies were tested by using IgG-ELISA test. It was shown that $74 \%$ of lupus nephritis patients showed positive results for anti-ds-DNA antibodies in their serum specimens $(p$-value $<0.01)$. Sensitivity and specificity of the anti-ds-DNA antibody test for the diagnosis of lupus nephritis were 74 and $100 \%$, respectively. Anaemia, hypoalbuminemia, fasting hyperglycemia and elevated blood urea nitrogen were significantly associated with lupus nephritis activity. Further studies are required to study genomic and unprecedented biomarkers associated with anti-dsDNA antibodies in patients with lupus nephritis to develop our perception of this autoimmune disease.
\end{abstract}

Keywords: Anti-dsDNA Antibodies, Lupus Nephritis, Renal Function Tests

\section{Introduction}

Systemic Lupus Erythematosus (SLE) is an autoimmune inflammatory disease characterized by multiple organs involvement and mostly affects women (HIM, 2015). Most severe lupus is manifested by entire kidney involvement. Lupus Nephritis (LN) is one of the most important complications of Systemic Lupus Erythematosus (SLE) disease. Structural and functional integrity of glomerular tissue could be affected by pathological changes accompanying lupus nephritis. Asymptomatic renal disease could be established by histological examination in most patients with lupus nephritis (Crow, 2011). Pathogenicity of LN is initiated primarily by deposition of glomerular immune complexes and production of autoimmune disease markers represented by the appearance of anti-dsDNA antibodies (Toong et al., 2011). A significant level of anti-dsDNA antibodies are detected in the majority of lupus patients by sophisticated immunological techniques. Deposition of anti-dsDNA antibodies in certain renal structures has been linked to disease severity (Yung and Chan, 2008). High sensitivity and specificity of anti-dsDNA antibodies were concluded by various studies concerning with accurate and early detection of renal involvement in lupus patients (Wichainun et al., 2013). However, a negative anti-dsDNA findings may be observed in many patients suspected with LN. Therefore, this issue should be kept in mind when interpreting such results (Wallace and Hahn, 2007). Healthy individuals and patients with other autoimmune disorders may be detected with positive antinuclear antibodies, although fair specificity has been observed in lupus nephritis cases. Persistent occurring of negative anti-dsDNA antibody findings should pay attention to other distinguishing clinical manifestations of autoimmune diseases (Fabrizio et al., 2015). 
It was shown that nearly $10-30 \%$ of severely affected patients with LN may sustain End-Stage Renal Disease (ESRD) (Ortega et al., 2010). Anaemia is one of the most important outcomes in ESRD patients presented with multifactorial causes (Giannouli et al., 2006).

The majority of patients with lupus nephritis may have abnormal findings of kidney function tests. Severe glomerular damage may be observed in some patients which usually requires prompt therapeutic interventions. Glomerular destruction may result in improper filtration of body wastes and extra fluids by kidneys (Ortega et al., 2010). Diagnostic and therapeutic approaches of LN are chiefly relay upon early detection of glomerular disruption through an accurate evaluation of kidney function tests (Dooley, 2007). Plasma proteins are increasingly excreted after glomerular injury in urine of LN patients. Albumin is the most considerable protein that excreted in severe glomerular destruction (Johnson, 2006).

A set of biochemical procedures are employed for the evaluation of renal function and waste filtering rate. Creatinine and blood urea nitrogen are among the most important laboratory tests for the screening of waste products in blood specimens. Elevation of creatinine level in blood more than normal values indicates a serious kidney problem. Estimation of Glomerular Filtration Rate (GFR) by a combination of blood and urine creatinine levels is an important screening test for evidence of kidney damage (Bargman, 2007).

In Iraq, although a number of studies have been conducted regarding SLE and lupus nephritis but information regarding association of anti-ds-DNA antibodies with abnormal renal function tests in patients with lupus nephritis are scarce. Possible correlation between anticardiolipin antibodies and complement component was recorded previously in a group Iraqi patients with lupus nephritis (Noor et al., 2007).

This study was designed for the detection of antiDNA antibodies in sera from patients with lupus nephritis and apparently healthy controls, study the possible relationship between anti-dsDNA antibody titers and abnormal renal function tests and to evaluate the severity of lupus nephritis according to certain hematological and biochemical estimates.

\section{Materials and Methods}

This study has been conducted at Al-Kadhimiyah Teaching Hospital and Al-Yarmook Teaching Hospital/Baghdad City from the period of July 2013 until December 2013.

Seventy patients with SLE were admitted to the AlKadhimiyah Teaching Hospital. All patients met the criteria of The American College of Rheumatology (ACR) (Hahn et al., 2012) for diagnosis of SLE. The diagnosis of SLE was done by specialized doctors, based on clinical examination and laboratory investigations that's including: General urine analysis with special consideration to urinary $\mathrm{RBC}$ count, $24 \mathrm{~h}$ urinary protein loss, hematological, biochemical tests and serological evidence of SLE. Lupus nephritis was defined as clinical and laboratory manifestations that met ACR criteria (persistent proteinuria $>0.5$ gm per day or greater than +3 by dipstick and/or cellular casts including red blood cells [RBCs], hemoglobin, granular, tubular, or mixed) (Hahn et al., 2012).

Additionally, a total of fifty apparently healthy controls were selected and investigated for comparison purposes. Venous blood samples $(5 \mathrm{~mL})$ were collected and labeled from study patients and controls for lab investigations. Part of each blood specimen $(2.5 \mathrm{~mL})$ was put in EDTA tube and was tested for hematological parameters which involved: Complete blood picture, blood group and Rh, PCV\%, hemoglobin electrophoresis and ESR. The other part of the blood specimen $(2.5 \mathrm{~mL})$ was collected in plastic disposable tubes and left to stand for 1.5 to $2 \mathrm{~h}$ at room temperature to allow clot, then it was centrifuged at $(1000 \mathrm{Xg})$ for $10 \mathrm{~min}$. The resulting serum was separated and frozen at $\left(-20^{\circ} \mathrm{C}\right)$ until time of analysis. Each sample was used just one time to avoid freezing and thawing.

The patient's sera samples were tested for the following biochemical tests:

\section{- $\quad$ Serum Urea}

- Serum Creatinine

- Total Serum Protein

- Serum Albumin

- $\quad$ Fasting Blood Sugar (FBS)

Anti-ds-DNA IgG enzyme-linked immunosorbent assay was conducted by using Euroimmun Anti-dsDNANcX ELISA (IgG) test kit. Assay procedure was applied according to manufacturer's instructions. According to Euroimmun recommendations, $\mathrm{IgG}$ antibody titer equal or more than $100 \mathrm{IU} \mathrm{mL}^{-1}$ was considered positive.

\section{Statistical Analysis}

Data analysis was performed by using Statistical Package for Social Sciences version 20 (SPSS Inc., Chicago, IL, USA). Comparison of differences between patients and control groups was performed by a $t$-test. A $P$ value $\leq 0.05$ was considered statistically significant.

\section{Results and Discussion}

Table 1 shows the distribution of study patients and healthy control group according to gender. It was clearly demonstrated that female patients were significantly higher than male patients, $53(76 \%)$ versus $17(24 \%) \quad(p$-value $<0.05)$. This result was in 
accordance with many other previously conducted studies (Yacoub Wasef, 2004; Feng et al., 2010). A lot of research has been done to study the effect of gender differences and hormonal effects on SLE development and activity. There were clear findings that female patients may be affected more than male patients with SLE. However, the issue remains obscure till now. In contrast, other studies show that lupus nephritis is worse and more frequently observed among men than female patients (Schwartzman-Morris and Putterman, 2012).

Table 2 shows the distribution of study patients and healthy control group according to age. It was clearly demonstrated that the age group 20-40 years comprised the highest percentage within all studied patients 31 (44\%), which indicate highly significant differences among age groups, $(p$-value $<0.01)$.

Several reports cited that SLE is most frequently observed within the age group of 15-40 years, although it may affects people in all age groups. In addition, the factor of female sex hormones are more commonly correlated with different SLE manifestations than age factor (Feng et al., 2010).

Frequency of anti-ds-DNA antibodies in serum samples from study patients and healthy controls is shown in Table 3. It was clearly demonstrated that $52(74 \%)$ of lupus nephritis patients showed positive results for antids-DNA antibodies in their serum specimens by ELISA test (p-value $<0.01$ ). The titers of antibody tested were equal or more than $100 \mathrm{IU} \mathrm{mL} \mathrm{m}^{-1}$ according to the cut-off value of Euroimmun kit. This result is in accordance with other previously conducted studies (Tsokos, 2011; Isenberg et al., 2007). Detection of this type of antinuclear antibodies is highly suggestive of SLE disease, but a negative result of these antibodies in patient's specimen does not exclude the presence of such a disease (Habash-Bseiso et al., 2005). Possible occurrence of anti-dsDNA antibody in asymptomatic lupus patients should pay attention that this test should not be relied upon as a definite parameter to follow up disease activity (Kavanaugh and Solomon, 2002).

Table 1. Distribution of study patients and healthy control group according to gender

\begin{tabular}{|c|c|c|c|c|c|c|}
\hline \multirow[b]{3}{*}{ Gender } & \multicolumn{6}{|c|}{ Studied group } \\
\hline & \multicolumn{2}{|c|}{ Lupus nephritis patients } & \multicolumn{2}{|c|}{ Apparently healthy controls } & \multicolumn{2}{|c|}{ Total } \\
\hline & No. & $\%$ & No. & $\%$ & No. & $\%$ \\
\hline Male & 17 & 24.3 & 5 & 10.0 & 22 & 18.3 \\
\hline Female & 53 & 75.7 & 45 & 90.0 & 98 & 81.7 \\
\hline Total & 70 & 100.0 & 50 & 100.0 & 120 & 100.0 \\
\hline
\end{tabular}

Table 2. Distribution of study patients and healthy control group according to age

\begin{tabular}{|c|c|c|c|c|c|c|}
\hline \multirow[b]{3}{*}{ Age groups } & \multicolumn{6}{|c|}{ Studied group } \\
\hline & \multicolumn{2}{|c|}{ Lupus nephritis patients } & \multicolumn{2}{|c|}{ Apparently healthy controls } & \multicolumn{2}{|c|}{ Total } \\
\hline & No. & $\%$ & No. & $\%$ & No. & $\%$ \\
\hline$<20$ years & 21 & 30.0 & 0 & 0.0 & 21 & 17.5 \\
\hline $20-40$ years & 31 & 44.3 & 50 & 100.0 & 81 & 67.5 \\
\hline $41-60$ years & 18 & 25.7 & 0 & 0.0 & 18 & 15.0 \\
\hline Total & 70 & 100.0 & 50 & 100.0 & 120 & 100.0 \\
\hline
\end{tabular}

Table 3. Frequency of anti-ds-DNA antibodies in serum samples from study patients and healthy controls

\begin{tabular}{|c|c|c|c|c|c|c|}
\hline \multirow{3}{*}{$\begin{array}{l}\text { Anti-ds-DNA } \\
\text { antibodies }\end{array}$} & \multicolumn{6}{|c|}{ Studied group } \\
\hline & \multicolumn{2}{|c|}{ Lupus nephritis patients } & \multicolumn{2}{|c|}{ Apparently healthy controls } & \multicolumn{2}{|c|}{ Total } \\
\hline & No. & $\%$ & No. & $\%$ & No. & $\%$ \\
\hline Positive & 52 & 74.3 & 0 & 0.0 & 52 & 43.3 \\
\hline Negative & 18 & 25.7 & 50 & 100.0 & 68 & 56.7 \\
\hline Total & 70 & 100.0 & 50 & 100.0 & 120 & 100.0 \\
\hline
\end{tabular}

Table 4. Sensitivity and specificity of anti-ds-DNA test in lupus nephritis patients

\begin{tabular}{ll}
\hline Percent & Item \\
\hline $74.3 \%$ & Sensitivity \\
$100 \%$ & Specificity \\
$100 \%$ & Positive predictive value \\
$73.5 \%$ & Negative predictive value \\
$85.0 \%$ & Accuracy \\
\hline
\end{tabular}


Table 4 shows sensitivity and specificity of antidsDNA test in lupus nephritis patients using ELISA test. It was clearly demonstrated that sensitivity and specificity of the test were 74 and $100 \%$, respectively. Many of previous studies recorded high specificity of ELISA anti-dsDNA antibodies in SLE patients (Wichainun et al., 2013). Three sophisticated techniques were previously evaluated by multiple studies for the detection of anti-ds DNA antibodies in SLE patients; radioimmunoassay, immunofluorescent and ELISA techniques. The advantages of ELISA in terms of safety, rapidity and easy to perform make it preferable in most laboratories for the detection of these antibodies. However, suspicions have been raised about the important and significant role of anti-dsDNA antibodies in the pathogenicity of SLE. Some researchers stressed that additional efforts are required for disclosing the exact pathogenic role of these antibodies in SLE (Isenberg et al., 2007).

Table 5 shows relationship between demographic, hematologic and biochemical parameters and positive anti-ds-DNA antibodies in lupus nephritis patients. It was clearly demonstrated that there were no statistical differences between study patients and healthy controls regarding total serum protein and serum creatinine concentrations ( $p$-value $>0.05$ ). Significant differences were observed regarding fasting blood sugar and blood urea concentrations ( $p$-value $>0.01)$. From the same table, highly significant differences were observed regarding $\mathrm{PCV} \%$ and serum albumin concentrations ( $\mathrm{p}$ value $<0.01)$. The hallmark of our results here is the existence of anaemia and decreased blood albumin in study patients. It was previously estimated that about fifty percent of lupus patients were afflicted with anaemia due to dyserythropoiesis which occurs in bone marrow. However, variable causes of anaemia could be evident in SLE patients with either immune or nonimmune origin (Giannouli et al., 2006).

Serum albumin concentration was detected in the range of $0.8-4.4 \mathrm{mg} \mathrm{mL} \mathrm{m}^{-1}$ in our study patients, indicating hypoalbuminemia and this result is in accordance with several previously conducted studies. Clinical manifestations of glomerular damage is frequently characterized by significant proteinuria and hypoalbuminemia (Sui et al., 2014). Evaluation of lupus nephritis activity is currently approached by a panel of biochemical analysis of kidney function in SLE patients. Nevertheless, significant relationship between these biochemical markers and lupus nephritis has not been established yet (Lee et al., 2013). The classical parameters for the detection of clinical outcomes of lupus nephritis such as anti-dsDNA, albumin and creatinine may not be accurate due to lack of sensitivity and specificity. Consequently, unprecedented biomarker tests are pivotal to promote the diagnostic accuracy and prognosis of lupus nephritis disease (Mok, 2010).

Table 5. Relationship between demographic, hematologic and biochemical parameters and positive anti-ds-DNA antibodies in lupus nephritis patients

\begin{tabular}{|c|c|c|c|c|c|}
\hline \multirow[b]{2}{*}{ Index } & \multirow[b]{2}{*}{ No. } & \multicolumn{2}{|l|}{ Range } & \multirow[b]{2}{*}{ t-test $p$-value } & \multirow[b]{2}{*}{ Significance } \\
\hline & & Minimum & Maximum & & \\
\hline \multicolumn{6}{|l|}{ Age/Year } \\
\hline - Lupus patients & 70 & 2.00 & 56.00 & 0.864 & NS \\
\hline - Healthy control & 50 & 20.00 & 40.00 & & \\
\hline \multicolumn{6}{|l|}{$\mathrm{Hb}(\mathrm{gm} / \mathrm{dl})$} \\
\hline - Lupus patients & 70 & 7.80 & 16.10 & 0.093 & NS \\
\hline - Healthy controls & 50 & 11.40 & 14.30 & & \\
\hline \multicolumn{6}{|l|}{ PCV\% } \\
\hline - Lupus patients & 70 & 25.00 & 50.00 & 0.001 & HS \\
\hline - Healthy controls & 50 & 35.00 & 49.00 & & \\
\hline \multicolumn{6}{|l|}{ FBS $(\mathrm{gm} / \mathrm{dl})$} \\
\hline - Lupus patients & 70 & 52.00 & 120.00 & 0.022 & $\mathrm{~S}$ \\
\hline - Healthy controls & 50 & 73.00 & 105.00 & & \\
\hline \multicolumn{6}{|l|}{ Serum albumin $(\mathrm{gm} / \mathrm{dl})$} \\
\hline - Lupus patients & 70 & 0.80 & 4.40 & 0.000 & HS \\
\hline - Healthy controls & 50 & 3.50 & 4.80 & & \\
\hline \multicolumn{6}{|c|}{ Total serum protein $(\mathrm{gm} / \mathrm{dl})$} \\
\hline - Lupus patients & 70 & 4.10 & 9.80 & 0.595 & NS \\
\hline - Healthy controls & 50 & 6.20 & 7.90 & & \\
\hline \multicolumn{6}{|l|}{ Blood urea (gm/dl) } \\
\hline - Lupus patients & 70 & 11.00 & 221.00 & 0.041 & $\mathrm{~S}$ \\
\hline - Healthy controls & 50 & 21.00 & 36.00 & & \\
\hline \multicolumn{6}{|c|}{ Serum creatinine $(\mathrm{gm} / \mathrm{dl})$} \\
\hline - Lupus patients & 70 & 0.35 & 6.44 & 0.153 & NS \\
\hline - Healthy controls & 50 & 0.70 & 0.88 & & \\
\hline
\end{tabular}




\section{Conclusion and Recommendation}

The study suggested that high frequency rate of anti-dsDNA antibodies were detected in patients with lupus nephritis. Anti-dsDNA antibodies have high specificity for the diagnosis of lupus nephritis. Anaemia, hypoalbuminemia, hyperglycemia and elevated blood urea were significantly associated with lupus nephritis activity. Further studies are required to study genomic and unprecedented biomarkers associated with anti-ds-DNA antibodies in patients with lupus nephritis to develop our perception of this autoimmune disease.

\section{Acknowledgement}

All staff member of the Teaching Laboratories of AlKadhimiyah Teaching Hospital and Al-Yarmook Teaching Hospital laboratory/Baghdad are acknowledged for their considerable assistance to complete this work.

\section{Authors' Contributions}

Falah Salim Manhal: Designed the study, wrote the protocol and wrote the first draft of the manuscript.

Hawra'a Adnan Mohammed: Managed the literature searches, performed the methodology of study and statistical analysis of results.

\section{Conflict of Interest}

Authors have declared that no competing interests exist.

\section{Ethical approval}

The present study was carried out with approval and agreement of Ethical and Medical Committee in College of Health \& Medical Technology/Baghdad.

\section{References}

Bargman, J.M., 2007. Why are rheumatologists treating lupus nephritis? Nat. Clin. Pract. Nephrol., 3: 296-297. DOI: $10.1038 /$ ncpneph0489

Crow, M.K., 2011. Systemic Lupus Erythematosus. In: Goldman's Cecil Medicine, Goldman, L. and A.I. Schafer (Eds.), Elsevier Saunders, Philadelphia.

Dooley, M.A., 2007. Clinical and Laboratory Features of Lupus Nephritis. In: Dubois' Lupus Erythematosus, Wallace, D.J. and B.H. Hahn (Eds.), Lippincott Williams and Wilkins, Philadelphia, pp: 1112-30.
Fabrizio, C., C. Fulvia, P. Carlo, M. Laura and M. Elisa et al., 2015. Systemic lupus erythematosus with and without anti-dsDNA antibodies: Analysis from a large monocentric cohort. Mediators Inflammat., 2015: 328078-328083.

DOI: $10.1155 / 2015 / 328078$

Feng, J.B., J.D. Ni, X. Yao, H.F. Pan and X.P. Li et al., 2010. Gender and age influence on clinical and laboratory features in Chinese patients with systemic lupus erythematosus: 1,790 cases. Rheumatol. Int., 30: 1017-23. DOI: 10.1007/s00296-009-1087-0

Giannouli, S., M. Voulgarelis, P.D. Ziakas and A.G. Tzioufas, 2006. Anaemia in systemic lupus erythematosus: From pathophysiology to clinical assessment. Ann. Rheum. Dis., 65: 144-8.

DOI: 10.1136/ard.2005.041673

Giannouli, S., M. Voulgarelis, P.D. Ziakas and A.G. Tzioufas, 2006. Anaemia in systemic lupus erythematosus: From pathophysiology to clinical assessment. Ann. Rheum. Dis., 65: 144-148.

DOI: 10.1136/ard.2005.041673

Habash-Bseiso, D.E., S.H. Yale, I. Glurich and J.W. Goldberg, 2005. Serologic testing in connective tissue diseases. Clin. Med. Res., 3: 190-193.

DOI: $10.3121 / \mathrm{cmr} .3 .3 .190$

Hahn, B.H., M.A. McMahon, A. Wilkinson, W.D. Wallace and D.I. Daikh et al., 2012. American college of rheumatology guidelines for screening, treatment and management of lupus nephritis. Arthritis Care Res., 64: 797-808. DOI: 10.1002/acr.21664

HIM, 2015. Harrison's Internal Medicine. 19th Edn., Chapter 378. Systemic Lupus Erythematosus. Accessmedicine.com. McGraw-Hill Education.

Isenberg, D.A., J.J. Manson, M.R. Ehrenstein and A. Rahman, 2007. Fifty years of anti-ds DNA antibodies: Are we approaching journey's end? Rheumatology, 46: 1052-1056. DOI: 10.1093/rheumatology/kem1 12

Johnson, A.M., 2006. Amino Acids, Peptides and Proteins. In: Tietz Textbook of Clinical Chemistry and Molecular Diagnostics, Burtis, C.A., E.R. Ashwood, D.E. Bruns (Eds.), St. Louis, Elsevier Saunders, pp: 533-554.

Kavanaugh, A.F. and D.H. Solomon, 2002. Guidelines for immunologic laboratory testing in the rheumatic diseases: Anti-DNA antibody tests. Arthritis Rheumatism, 47: 546-555. DOI: 10.1002/art.10558

Lee, J.Y., S.H. Chang, H.J. Oh, Y.Y. Lee and M.J. Kang et al., 2013. Proteomic approach and validation of urinary biomarkers in lupus nephritis. Arthritis Rheum., 65: 637-637.

Mok, C.C., 2010. Biomarkers for lupus nephritis: A critical appraisal. J. Biomed. Biotechnol., 2010: 638413-638423. DOI: $10.1155 / 2010 / 638413$ 
Noor, N.A.A., K.M. Mousawy, A.R. Al-Derzi and M.A.A. Al-Faham, 2007. Evidence of correlation between some auto antibodies with complement component in lupus nephritis. Iraqi Postgraduate Med. J., 6: 54-57.

Ortega, L.M., D.R. Schultz, O. Lenz, V. Pardo and G.N. Contreras, 2010. Lupus nephritis: Pathologic features, epidemiology and a guide to therapeutic decisions. Lupus, 19: 557-574. DOI: $10.1177 / 0961203309358187$

Schwartzman-Morris, J. and C. Putterman, 2012. Gender differences in the pathogenesis and outcome of lupus and of lupus nephritis. Clin. Dev. Immunol., 2012: 604892-604900. DOI: 10.1155/2012/604892

Sui, M., X. Jia, C. Yu, X. Guo and X. Liu et al., 2014. Relationship between hypoalbuminemia, hyperlipidemia and renal severity in patients with lupus nephritis: A prospective study. Central Eur. J. Immunol., 39: 243-252. DOI: $10.5114 /$ ceji.2014.43730

Toong, C., S. Adelstein and T.G. Phan, 2011. Clearing the complexity: Immune complexes and their treatment in lupus nephritis. Int. J. Nephrol. Renovasc. Dis., 4: 17-28.

DOI: $10.2147 /$ IJNRD.S10233
Tsokos, G.C., 2011. Systemic lupus erythematosus. New Engl. J. Med., 365: 2110-2121.

DOI: $10.1056 /$ NEJMra1 100359

Wallace, D.J. and B. Hahn, 2007. Dubois' Lupus Erythematosus. 1st Edn. Lippincott Williams and Wilkins, ISBN-10: 0781793947, pp: 1414.

Wichainun, R., N. Kasitanon, S. Wangkaew, S. Hongsongkiat and W. Sukitawut et al., 2013. Sensitivity and specificity of ANA and anti-dsDNA in the diagnosis of systemic lupus erythematosus: A comparison using control sera obtained from healthy individuals and patients with multiple medical problems. Asian Pac. J. Allergy Immunol., 31: 292-8. PMID: 24383972

Yacoub Wasef, S.Z., 2004. Gender differences in systemic lupus erythematosus. Gend. Med., 1: 12-7. DOI: $10.1016 / \mathrm{S} 1550-8579(04) 80006-8$

Yung, S. and T.M. Chan, 2008. Anti-DNA antibodies in the pathogenesis of lupus nephritis-the emerging mechanisms. Autoimmun Rev., 7: 317-21.

DOI: 10.1016/j.autrev.2007.12.001 